\title{
Local Injection of Endothelin-1 Produces Pain-Like Behavior and Excitation of Nociceptors in Rats
}

\author{
Alexander P. Gokin, ${ }^{1,2}$ Moin U. Fareed,, ${ }^{1,3}$ Hui-Lin Pan, ${ }^{4}$ Guy Hans,, ${ }^{1,3}$ Gary R. Strichartz, ${ }^{2,3}$ and Gudarz Davar ${ }^{1}$ \\ ${ }^{1}$ Molecular Neurobiology of Pain, and 2 Sensory Neurophysiology Laboratories of the Pain Research Center, Department \\ of Anesthesiology, Perioperative and Pain Medicine, Brigham and Women's Hospital, Boston, Massachusetts 02115, \\ ${ }^{3}$ Department of Biological Chemistry and Molecular Pharmacology, Harvard Medical School, Boston, Massachusetts \\ 02115, and 4Department of Anesthesiology, Physiology and Pharmacology, Wake Forest University School of Medicine, \\ Winston-Salem, North Carolina 27157
}

Neurobehavioral and neurophysiological actions of the peptide endothelin-1 (ET-1) were investigated after subcutaneous plantar hindpaw injections in adult male Sprague Dawley rats. Hindpaw flinching developed within minutes after ET-1 (8-16 $\mathrm{nmol}$ ) injection, peaked at $30 \mathrm{~min}$, lasted for $60 \mathrm{~min}$, and was strongly inhibited by the endothelin- $A\left(E T_{A}\right)$ receptor antagonist, BQ-123 (3.2 M). In separate experiments, impulse activity of single, physiologically characterized sensory $\mathrm{C}-, \mathrm{A} \delta$-, and $\mathrm{A} \beta$-fibers was recorded from the sciatic nerve in anesthetized rats after subcutaneous injections of endothelin-1 (1-20 nmol), alone or together with $\mathrm{BQ}-123(3.2 \mathrm{M})$, into the plantar hindpaw receptive fields of these units. All nociceptive C-fibers (31 of 33 C-fibers studied) were excited by ET-1 (1-20 nmol) in a dosedependent manner. For doses of 16-20 nmol, the mean latency for afferent activation after injection of ET-1 was $3.16 \pm 0.31$ min, and the mean and maximum response frequency were $2.02 \pm 0.48 \mathrm{impulses}(\mathrm{imp}) / \mathrm{sec}$ and $14.0 \pm 3.2 \mathrm{imp} / \mathrm{sec}$, respectively. All 10 nociceptive $A \delta$-fibers (of $12 \mathrm{~A} \delta$-fibers studied) also responded to 1-20 nmol of ET-1 in a dose-dependent manner with a mean latency of $3.5 \pm 0.12 \mathrm{~min}$ and mean response frequency of $3.3 \pm 2.3 \mathrm{imp} / \mathrm{sec}$. In contrast, most $\mathrm{A} \beta$-fibers (9 of 12) did not respond to ET-1. BQ-123, when coinjected with ET-1, blocked ET-1-induced activation in all Cand $A \delta$-fibers tested. These data demonstrate that subcutaneous administration of ET-1 to the rat plantar hindpaw produces pain-like behavior and selective excitation of nociceptive fibers through activation of $\mathrm{ET}_{\mathrm{A}}$ receptors.

Key words: excitability; peripheral nerve; algogenic; C-fiber; nociceptor; cancer
Pain is a frequent and disabling consequence of metastatic prostate and breast cancer in humans. The cause of this pain is unknown but may involve mediator-dependent signaling by tumor cells to spinal nerve roots. One candidate mediator, the potent vasoconstrictive peptide and mitogen endothelin-1 (ET-1), is secreted in high concentrations by metastatic prostate and breast cancer cells and is known to induce pain-like behavior in animals and pain in humans (Ferreira et al., 1989; Dahlof et al., 1990; Hammerman et al., 1997; Piovezan et al., 1997, 2000; Carducci et al., 1998; Davar et al., 1998; De-Melo et al., 1998; GraidoGonzalez et al., 1998; Fareed et al., 2000; Jarvis et al., 2000). ET-1 is also found in high concentration in both dorsal root ganglion neurons (Giaid et al., 1989) and satellite cells (Kar et al., 1991), whereas endothelin- $\mathrm{A}\left(\mathrm{ET}_{\mathrm{A}}\right)$ receptors are found on small to medium sized dorsal root ganglion neurons and their axons (Pomonis et al., 2001), which is further evidence supporting a potential role for ET-1 in pain signaling. In rodents, intraperitoneal administration of ET-1 produces pain behavior that is ET receptor-mediated (Raffa et al., 1996a,b), whereas intra-articular administration of ET-1 in dogs produces pain behavior and hy-

\footnotetext{
Received Feb. 8, 2001; revised April 13, 2001; accepted May 3, 2001.

This work was supported by funds from United States Public Health Service Grant CA 80153. We gratefully acknowledge the participation of Catherine Sinnott in the performance of these experiments.

A.P.G. and M.U.F. contributed equally to this work.

Correspondence should be addressed to Dr. Gudarz Davar, Molecular Neurobiology of Pain Laboratory, Department of Anesthesia, Brigham and Women's Hospital, 75 Francis Street, Boston, MA 02115. E-mail: gdavar@zeus.bwh.harvard.edu. Copyright (C) 2001 Society for Neuroscience $0270-6474 / 01 / 215358-09 \$ 15.00 / 0$
}

peralgesia (Ferreira et al., 1989). Similarly, in mice, intraplantar ET-1 potentiates pain states in models of chemical- and inflammation-induced pain (Piovezan et al., 1997; De-Melo et al., 1998). In humans, ET-1 injected into the brachial artery induced severe pain and prolonged, touch-evoked allodynia (Dahlof et al., 1990), and Carducci et al. (1998) have reported that an endothelin-A receptor antagonist can reduce verbal reports of pain in patients with metastatic prostate cancer.

In support of these findings in animals and humans, we have recently described neurobehavioral effects of ET-1 applied extraneurally or intraneurally to rat sciatic nerve (Davar et al., 1998; Fareed et al., 2000). These experiments showed that ET-1 induces hindpaw flinching behavior in rats that is dose dependent and mediated by $\mathrm{ET}_{\mathrm{A}}$ receptors, and that it may be attributable to direct actions on primary afferents.

To establish the selectivity of the actions of ET-1 for excitation of functionally identified peripheral axons, we have now studied whether ET-1 applied subcutaneously to the rat plantar hindpaw can produce hindpaw flinching that is accompanied by spike activity in single primary afferents supplying the plantar hindpaw. We have also determined whether an $\mathrm{ET}_{\mathrm{A}}$ receptor antagonist can block ET-1-induced flinching behavior or spike activity in identified primary afferents.

\section{MATERIALS AND METHODS}

The use of animals in these experiments was approved by the Standing Committee on Animals at Harvard Medical School. Animals were treated and cared for according to the ethical standards and guidelines for investigations of experimental pain in animals prescribed by the 
Committee for Research and Ethical Issues of the International Association for the Study of Pain (Zimmermann, 1983).

\section{Neurobehavioral experiments}

ET-1 and an ET $T_{A}$ receptor antagonist administration. Synthetic ET-1 (98\% pure peptide content; American Peptides, Sunnyvale, CA) dissolved in PBS (Life Technologies-BRL, Grand Island, NY), pH 7.4, was injected in a $40 \mu \mathrm{l}$ volume into the subcutaneous plantar hindpaw of adult (200-225 gm), male Sprague Dawley rats (Harlan, Indianapolis, IN) anesthetized briefly with sevofluorane. To minimize rapid absorption of ET-1 from the injection site, the hindlimb was cooled with a small amount of a packed ice-water mix in a $15 \mathrm{ml}$ polypropylene centrifuge tube (Corning Inc., Corning, NY) placed beneath the limb; a small amount of wet ice wrapped in cotton gauze was also placed on top of the hindlimb. ET-1 (for $200 \mu \mathrm{M}, n=12$; for $300 \mu \mathrm{M}, n=11$; for $400 \mu \mathrm{M}, n=13$ animals) or vehicle (PBS, $n=10)$ was administered in three divided doses $(10,20$, and $10 \mu \mathrm{l}$ at 0,5 , and $9 \mathrm{~min}$, respectively). After completion of injections, animals were allowed to recover completely from anesthesia for $5 \mathrm{~min}$ before behavioral observations began.

To establish that the pain-inducing actions of subcutaneously administered ET-1 was $\mathrm{ET}_{\mathrm{A}}$ receptor dependent, a selective antagonist of the $\mathrm{ET}_{\mathrm{A}}$ receptor (BQ-123; American Peptides) was injected in a solution containing a final concentration of $3.2 \mathrm{~mm} \mathrm{BQ}-123$ alone, $20 \mathrm{~min}(20 \mu \mathrm{l})$ and $10 \mathrm{~min}(20 \mu \mathrm{l})$ before the cessation of anesthesia, and then together with $400 \mu \mathrm{M}(n=7)$ or $200 \mu \mathrm{M} \mathrm{ET-1}(n=5)$ in three doses over a 9-10 min period. The concentration chosen for this antagonist was well in excess of its $\mathrm{K}_{\mathrm{I}}(10 \mathrm{~nm})$, which was determined directly in other tissues (Ishikawa et al., 1992; Marsault et al., 1993).

Behavioral measurements. Behavioral assessments were performed as described previously (Davar et al., 1998), with animals freely moving on a flat surface that was enclosed by an inverted, large Plexiglas cage. Repetitive and spontaneous flinching of the hindpaw (rapid lifting of the entire hindlimb that begins with hip flexion and includes dorsiflexion of the toes) was measured beginning 5 min after ET-1 administration. The number of these hindpaw flinches occurring every 5 min was measured over the next $60 \mathrm{~min}$.

\section{Neurophysiological experiments}

Surgery and anesthesia. Neurophysiological experiments were conducted on 30 adult, male Sprague Dawley rats weighing 250-300 gm (Taconic Laboratories, Germantown, NY, and Harlan). Rats were initially anesthetized with urethane $(1.3 \mathrm{gm} / \mathrm{kg}$, i.p.) (Sigma, St. Louis, MO) or sodium pentobarbital $(50-60 \mathrm{mg} / \mathrm{kg})$. The left carotid artery and right or left jugular vein were cannulated for continuous monitoring of blood pressure and to permit intravenous administration of additional doses of pentobarbital (10-20 mg/kg, i.v.) or chloralose $(15 \mathrm{mg} / \mathrm{kg}$, i.v.) to maintain general anesthesia. Anesthetic dosing was titrated to the absence of corneal reflexes, heart rate, withdrawal reflexes to noxious stimuli, and blood pressure fluctuations. Heart rate was monitored with a Tektronix 498 EKG Monitor (Tektronix, Beaverton, OR). Tracheotomy was performed for artificial respiration. During recordings, rats were immobilized with pancuronium bromide (Sigma; $1 \mathrm{mg} \cdot \mathrm{kg}^{-1} \cdot \mathrm{hr}^{-1}$, i.v.) and artificially ventilated via a respirator (RSP1002, Kent Scientific Corporation). End-tidal $\mathrm{CO}_{2}$ was continuously monitored with an end-tidal $\mathrm{CO}_{2}$ analyzer (IITC Life Science, Woodland Hills, CA) and maintained at $4-4.5 \%$. In some experiments, arterial blood gases were sampled and analyzed with a blood gas analyzer. Core body temperature was monitored by a rectal thermometer and maintained at $36-37.5^{\circ} \mathrm{C}$ with a circulating water heating pad and heat lamps. At the end of an experiment, rats were euthanized with an overdose of sodium pentobarbital (100-200 mg/kg, i.v.).

Recording procedures. Single-unit nerve activity was recorded from the left or right sciatic nerve. A restricted skin incision was made over the posterior hindlimb, and the skin and muscle were opened to expose the middle and distal part of the sciatic nerve. Rats were then placed in a stereotaxic frame (David Kopf Co.) to immobilize the lower spine and pelvis. The hindlimb was not cooled as in neurobehavioral experiments because spike responses (see Results) were easily obtained with subcutaneous injection of ET-1. The skin at the incision was sewn to a metal ring to form a pool. The fascia and sheath overlying the sciatic nerve were carefully removed, and the nerve was placed on a platform and covered with warm mineral oil. Small nerve filaments, transected proximally, were teased gently from the sciatic under a dissecting microscope (Carl Zeiss, Thornwood, NY). Isolated fine filaments were then wrapped around a silver wire recording electrode, which was connected to a high impedance probe. One or two such electrodes were used for recording from one or two separate microfilaments. Reference electrodes were placed on the surrounding tissues.

The action potential of an isolated afferent fiber was amplified 20,000$50,000 \times$, filtered with a bandwidth of $100-300$ to $1000-1500 \mathrm{~Hz}$ (Grass P511 or W PI DAM8 amplifier), and processed through an audio amplifier and an oscilloscope. Nerve impulse activity and blood pressure were simultaneously recorded on a K2G thermal recorder (Astro-Med, W. Warwick, RI). Nerve activity also was fed into a PC-compatible computer through an analog-to-digital interface board for subsequent off-line quantitative analysis. Discharge frequency was counted by using window discriminator (DataWave Technology, Longmont, CO, or Spike-2, Cambridge Electronics Design, Cambridge, UK), and a histogram was created for each fiber. Accurate counting of the discharge frequency was verified for each fiber by comparing the constructed histogram with the hardcopy recorded simultaneously. The nerve activity is presented here in two forms: as native records and as bin histograms (see, for example, Fig. 3).

Isolation, identification, and classification of fibers. To search for units we used two approaches: (1) electrical stimulation of sciatic nerve fibers at a site between the recording site and the fiber's receptive field (RF) and (2) mechanical stimulation of their hindpaw RFs. Electrical stimulation was performed either with silver electrodes placed beneath the most distal part of the exposed sciatic nerve or with transcutaneous needle electrodes. One pair of transcutaneous electrodes was placed in the heel area to permit multiunit stimulation of plantar and sural nerve fibers. Another pair of fine needle electrodes was placed just proximal to the RFs of identified units. Stimulus duration was $0.2 \mathrm{msec}$ for $\mathrm{A} \beta$ - and A $\delta$-fibers and $0.5-0.75 \mathrm{msec}$ for $\mathrm{C}$-fibers. The amplitude of stimuli was usually set at 1.5 times the fiber response threshold, whereas the frequency of stimuli was usually $1 \mathrm{~Hz}$. Responses to natural stimulation of their RFs and conduction velocity $(\mathrm{CV})$ of fibers were the main criteria used for physiological characterization and classification. Two types of mechanical stimulation of RFs were used: (1) noncalibrated search stimuli such as stroking, tapping, or moderately firm pressure applied with a cotton-tipped swab to plantar surfaces and (2) stimuli using calibrated von Frey hairs (Stoelting, Wood Dale, IL) for more precise physiological characterization of units. In addition, light brushing and pinching with nonserrated forceps were also used for low- and high-intensity mechanical stimulation, respectively (see Fig. 3). Conduction velocities were calculated by dividing the distance between the stimulating and recording electrodes by the latency of the electrically evoked spike. Units with $\mathrm{CVs}>20 \mathrm{~m} / \mathrm{sec}$ were identified as A $\beta$-fibers, units with CVs of 2.2-20 $\mathrm{m} / \mathrm{sec}$ were identified as A $\delta$-fibers, and units with $\mathrm{CVs}<2 \mathrm{~m} / \mathrm{sec}$ were identified as C-fibers (Sanders and Zimmermann, 1986; Handwerker et al., 1991; Leem et al., 1993; Huang et al., 1997). C-fibers were classified as high-threshold mechanoreceptors (HTMs) if they fired in response to a strong pinch of the skin with forceps, perceived as painf ul when applied to the authors; these HTMs were defined as nociceptors. Units that responded to light stroking by a soft-bristled brush but not to pinch were non-nociceptive units, which were almost never $\mathrm{C}$ - or $\mathrm{A} \delta$-fibers but most often $\mathrm{A} \beta$-fibers. To confirm that we were recording from a single (the same) unit, a modification of the methods of Iggo (1958) was used. In this procedure, electrical stimulation is applied to the RF of a unit at the same time as repeated physiologic stimulation. If electrical stimulation occurs during the refractory period for impulses generated by a previous physiologic stimulus, the spike response is blocked.

In some instances, the thermal threshold of recorded afferents was determined. After the receptive field was located on the skin, a $1 \mathrm{~cm}^{2}$ Peltier-controlled thermode (Yale University, New Haven, CT), maintained at $30^{\circ} \mathrm{C}$, was gently placed on the surface of the skin. Thermal stimulation was performed by increasing the probe surface temperature from 38 to $51^{\circ} \mathrm{C}$, in $1^{\circ} \mathrm{C}$ increments for $5 \mathrm{sec}$ every $30 \mathrm{sec}$. The probe temperature was allowed to return to baseline between successive stimuli. The minimal temperature required to stimulate the afferent was considered as the thermal threshold. This threshold was measured at least twice, separated by $10-12 \mathrm{~min}$, to ensure reproducibility. The thermal responsiveness of several additional units was also determined by applying a heated metal spatula $\left(\sim 52^{\circ} \mathrm{C}\right)$ and a piece of ice (cold stimulation) to the cutaneous RF. On the basis of their responses to different stimuli (and their CVs), all units studied were classified as (1) polymodal (mechano-heat) nociceptors (mainly associated with C-fibers: C-PMNs), (2) high-threshold mechanoresponsive C- and A $\delta$-fibers for which thermal responsiveness was not checked (HTMr), and (3) nonnociceptive mechanoreceptors (mainly $\mathrm{A} \beta$ - and a few $\mathrm{A} \delta$ - and $\mathrm{C}$-fibers). 
Drug doses and injection procedures. As described above in Neurobehavioral experiments, an ET-1 stock solution was prepared to $400 \mu \mathrm{M}$ in PBS, pH 7.4. BQ-123 was dissolved in PBS to obtain a $6.4 \mathrm{~mm}$ stock, which was kept frozen and prepared for injection ex tempore by adding the stock to an equal volume of $400 \mu \mathrm{M}$ ET-1 solution to produce a final concentration of $200 \mu \mathrm{M}$ of ET-1 and $3.2 \mathrm{mM}$ BQ-123. ET-1 and ET-1 together with BQ-123 were applied via subcutaneous microinjections into or in the immediate vicinity (within 1-2mm) of the RF of a fiber's. ET-1 was initially injected as a single $50 \mu \mathrm{l}$ bolus of a $400 \mu \mathrm{M}$ solution (20 nmol) and then, in an effort to better mirror the neurobehavioral experiments, in multiple (4) $10 \mu \mathrm{l}$ volumes of a $400 \mu \mathrm{M}$ solution. To establish the concentration dependence of the effects of ET-1, progressively lower concentrations of ET-1 were administered as $2 \times 10 \mu \mathrm{l}$ of $400 \mu \mathrm{M}$ solution $(8 \mathrm{nmol})$ and $1 \times 10 \mu \mathrm{l}$ of $200 \mu \mathrm{M}$ solution $(2 \mathrm{nmol})$. All injections were performed over a 1-4 min duration. No significant differences in spike response to ET-1 injection were observed between the single and multiple injection procedures at the $400 \mu \mathrm{M}$ concentration (data not shown). Vehicle controls were also performed as single or multiple injections, either as PBS alone or PBS before ET-1 injection. Recording continued in most instances for $40 \mathrm{~min}$ to $2 \mathrm{hr}$ after administration of drugs.

Data analysis. The total number of hindpaw flinches was determined during a 60 min observation period, which was divided into 12 periods of 5 min each, after subcutaneous injection of ET-1 into the plantar hindpaw. To detect interactions between the experimental groups, an ANOVA (StatView 4.5, SAS Institute, Cary, NC) statistical analysis was performed. When significant $F$ ratios were found, all possible pairwise comparisons were performed using a multiple $t$ statistic (Fisher's protected least significant difference).

A responding unit was defined as one that began to fire after injection was complete and the needle had been withdrawn. The latency of spike response was measured as the time from the end of ET-1 injection (last injection in the case of multiple injections) to the onset of the first nonelectrically evoked response. The duration of responses was measured from the onset of response until afferent activity returned to baseline. Mean response frequency (MRF, impulses per second) was calculated as the number of spikes divided by the duration of the entire ET-1-induced response. To characterize responses within bursting patterns, maximum frequency $(\mathrm{MxF})$ was determined as the number of spikes within a brief $(1 \mathrm{sec})$ interval of rapid firing. Duration and MRF were used as quantitative parameters for comparing the magnitudes of responses to different doses of ET-1. All of the results are presented as means \pm SEM. One-way ANOVA was used to evaluate the significance of the difference of means. The ratio of responding to nonresponding units between different classes of fibers was compared using a $\chi^{2}$ contingency table. Differences were considered statistically significant at $p<0.05$.

\section{RESULTS}

\section{Dermatologic effects}

Subcutaneous administration of ET-1 (200-400 $\mu \mathrm{M})$ to the rat plantar hindpaw produced an area of blanching within minutes at the site of injection $\left(2.5 \mathrm{~mm}^{2}\right)$. A larger area $\left(7.5 \mathrm{~mm}^{2}\right)$ of erythema could be observed beginning 15-20 min after ET-1 administration that progressed to diffuse rubor of the hindpaw that lasted for $60 \mathrm{~min}$ and then resolved. Animals occasionally demonstrated signs of stress (red tears) beginning near the end of the 60 min period of observation, which was likely caused by systemic effects of ET-1. Lowering the concentration (200-300 $\mu \mathrm{M})$ of ET-1 minimized these signs of stress while preserving pain behavior (see below). Animals $(n=3)$ showing significant signs of toxicity at $400 \mu \mathrm{M} \mathrm{ET-1} \mathrm{(red} \mathrm{tears} \mathrm{and} \mathrm{reduced} \mathrm{exploration)}$ were not included in the data analysis.

\section{Neurobehavioral effects}

Subcutaneous injection of $40 \mu \mathrm{l}$ of PBS into the subcutaneous plantar hindpaw produced minimal evidence of hindpaw flinching (Fig. 1). In comparison, subcutaneous injection of ET-1 produced dose-dependent ipsilateral hindpaw flinching identical in appearance to that observed previously after application of ET-1 to rat sciatic nerve (Davar et al., 1998; Fareed et al., 2000). Hindpaw

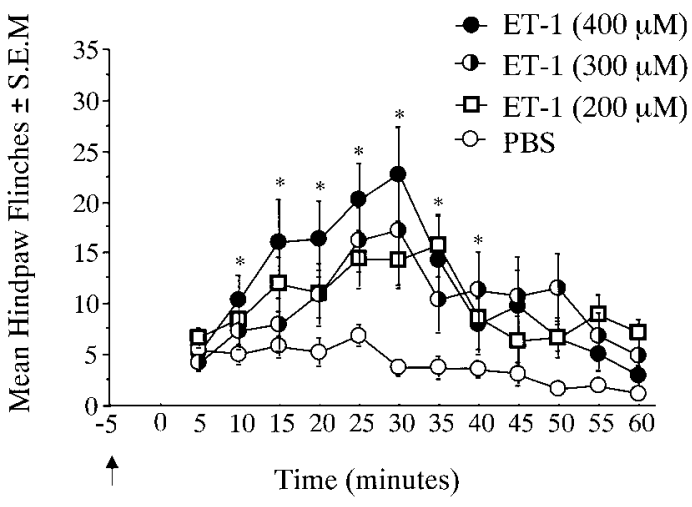

Figure 1. Hindpaw flinching induced by the injection of 8,12 , and 16 nmol ( $n=10$ animals for each dose) ET-1 (equivalent to 200, 300, and 400 $\mu \mathrm{M}$, respectively) subcutaneously into the rat plantar hindpaw. Termination of ET- 1 administration was at $t=-5 \mathrm{~min}$; animals were allowed 5 min to recover before assessments began. The frequency of hindpaw flinching occurring every $5 \mathrm{~min}$, measured from $t=0$, over a period of 60 min was determined. Differences between $400 \mu \mathrm{M}$ ET-1 and PBS were present from 10 to $40 \mathrm{~min}$ after observations began $\left({ }^{*} p<0.05\right.$; f-ANOVA, StatView).

flinching was observed from 10 until 40 min after the onset of observations in at least 10 animals receiving $400 \mu \mathrm{M}$ ET-1 (Fig. 1). Treatment with $300 \mu \mathrm{M}$ ET-1 resulted in a significant difference with control animals between 25 and 35 min when compared with $200 \mu \mathrm{M}$ (Fig. 1). When BQ-123 was administered subcutaneously in multiple doses both before and at the time of ET-1 (200 or 400 $\mu \mathrm{M})$ injection, it completely blocked hindpaw flinching during the entire period of observation (Fig. 2).

\section{Neurophysiological effects}

We recorded impulse activity from 68 single, physiologically characterized afferent fibers of different classes: C-fibers $(n=$ $38)$, A $\delta$-fibers $(n=16)$, and A $\beta$-fibers $(n=14)$, before and after subcutaneous injections of ET-1 alone or with BQ 123 into their RFs. The fibers were examined in three series of experiments: first, with the same $(16 \mathrm{nmol})$ or slightly higher $(20 \mathrm{nmol})$ doses of ET-1 than those used in behavioral studies; second, with lower doses (1-8 nmol); and finally, with $16 \mathrm{nmol}$ of ET-1 together with BQ 123. RFs of fibers were primarily located on the glabrous surface of the plantar hindpaw (except in a few instances when

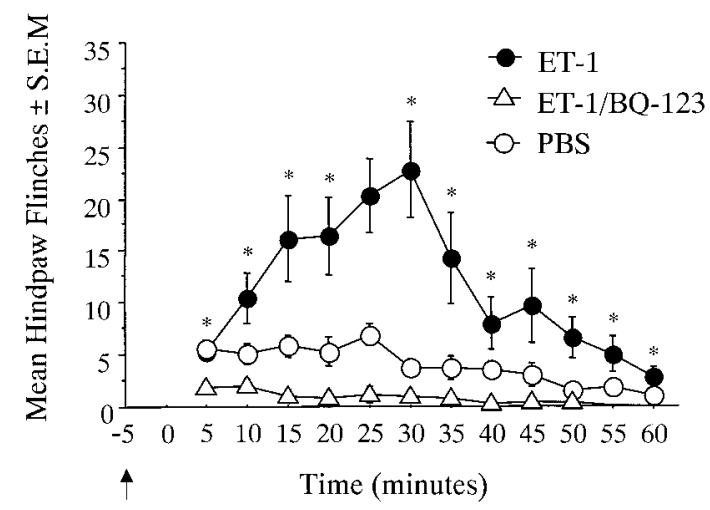

Figure 2. Blockade of ET-1-induced hindpaw flinching by subcutaneous BQ-123 (3.2 mM) applied together with ET-1 $(400 \mu \mathrm{M})$ over a 9-10 min period. Termination of ET-1 + BQ-123 administration was at $t=-5 \mathrm{~min}$; animals were allowed $5 \mathrm{~min}$ to recover before assessments began. Differences between ET-1/BQ-123-treated and ET-1-treated animals are significant at all time points $\left({ }^{*} p<0.05\right.$; f-ANOVA, StatView). 
A
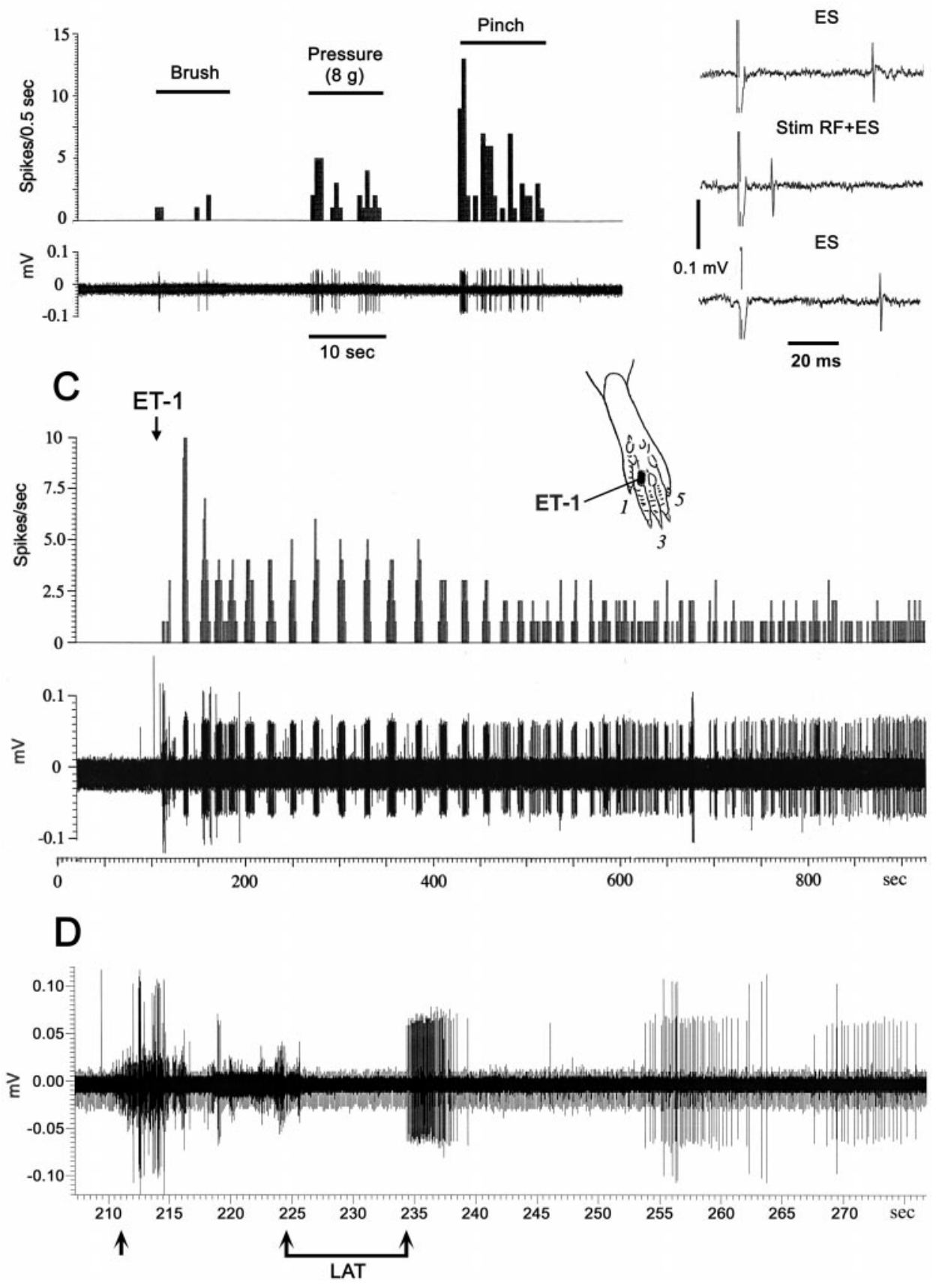

Figure 3. Excitation of an HTMr C-fiber after subcutaneous injection of ET-1 into the rat plantar hindpaw. $A$, Physiological characterization of an HTMr C-fiber (CV 0.72 $\mathrm{m} / \mathrm{sec}$ ) showing the fiber response to graded mechanical stimulation (below), presented also as a bin histogram (above). B, Procedure for confirming single unit activity. Top and bottom traces, Spikes are evoked by transcutaneous electrical nerve stimulation $(E S)$ that has a consistent latency of $63 \mathrm{msec}$; middle trace, the electrically evoked spike fails to appear, presumably because of the refractory period generated by the spike evoked by mechanical stimulation of the receptive field. $C$, Representative $\mathrm{C}$-fiber response $(\mathrm{CV} 1.8 \mathrm{~m} / \mathrm{sec})$ to the subcutaneous injection of $2 \mathrm{nmol}(10 \mu \mathrm{l}$ of $200 \mu \mathrm{M})$ of ET-1 (below), presented also as a bin histogram (above). Note the short latency to onset of spiking, and the "bursting" pattern of this spike activity occurring within the first 10 min of the response. Inset shows the location of the receptive field of this unit. $D, \mathrm{Ex}-$ panded time scale of the early response to ET-1 (shown in $C$ ) illustrating the approach to latency measurement. The arrow points to the beginning of injection, whereas the twin arrows and intervening line denote the end of injection (needle withdrawal) and latency $(L A T)$ to the first measured spike response. they were located on the ankle, at the border between glabrous and hairy skin on the plantar hindpaw and, in one instance, on the leg) (Figs. 3, 6, 7, insets). These RFs were within regions that are primarily innervated by the plantar and sural nerves, and they ranged in size from $1 \times 2 \mathrm{~mm}$ to $3 \times 4 \mathrm{~mm}$ for $\mathrm{C}$ - and $\mathrm{A} \delta$-fibers, and from $2 \times 3 \mathrm{~mm}$ up to $7 \times 10 \mathrm{~mm}$ for $\mathrm{A} \beta$-fibers. The conduction velocities of $\mathrm{C}$-units ranged from 0.47 to $1.8 \mathrm{msec}$ (mean $0.91 \pm 0.05 \mathrm{msec}$ ), of A $\delta$-fibers from 2.2 to $12.8 \mathrm{msec}$ $(6.9 \pm 1.0 \mathrm{msec})$, and of $\mathrm{A} \beta$-fibers from 23 to $51 \mathrm{msec}(32.5 \pm 2.0$ msec). The vast majority of $\mathrm{C}$-, $\mathrm{A} \delta$-, and $\mathrm{A} \beta$-fibers $(82,72$, and $81 \%$, respectively) had no ongoing spontaneous activity. In those units in which spontaneous activity was observed, the mean frequency was very low $(0.04-0.17 \mathrm{imp} / \mathrm{sec})$.

\section{Effects of ET-1 on C-fibers}

In control experiments, seven C-units (all HTMr) were injected with PBS (2 with $50 \mu$ l and 5 with $10 \mu$ ) (Table 1). Two responded to $\mathrm{PBS}$, one (50 $\mu$ l volume) very weakly $(\mathrm{MRF}=0.12$ $\mathrm{imp} / \mathrm{sec})$ and briefly ( $<2 \mathrm{~min})$ and the other $(10 \mu$ l volume $)$ with MRF significantly lower $(0.34 \mathrm{imp} / \mathrm{sec})$ than that observed after subsequent injection of a low concentration of ET-1 (1 nmol in 10 $\mu$ PBS) into the same unit (2.25 imp/sec) (data not shown).

Most C-fibers in which the effects of ET- 1 were examined (20 of 33) responded to strong (18-52 gm von Frey hair) mechanical stimulation of their RFs, whereas 11 of 33 began to fire with weak initial stimulation (2.26-5.25 gm) but increased their responses 
Table 1. Parameters of spike responses of afferent fibers to subcutaneous ET-1 and PBS

ET-1

Number of units responding/ total units studied

\begin{tabular}{|c|c|c|c|c|c|c|}
\hline \multirow[b]{2}{*}{$\begin{array}{l}\text { Fiber class } \\
\text { (range of } \mathrm{CV} \text { ) }\end{array}$} & \multicolumn{2}{|c|}{ 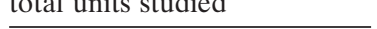 } & \multicolumn{3}{|c|}{ 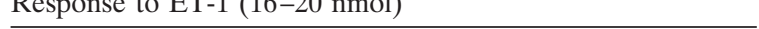 } & \multirow{2}{*}{$\begin{array}{l}\text { Number of units } \\
\text { responding/total } \\
\text { units studied }\end{array}$} \\
\hline & $1-8 \mathrm{nmol}$ & $16-20 \mathrm{nmol}$ & $\begin{array}{l}\text { MRF } \\
\text { (imp/sec) }\end{array}$ & $\begin{array}{l}\text { Maximum response } \\
\text { frequency }\left(\mathrm{imp} / \mathrm{sec}^{1}\right)\end{array}$ & $\begin{array}{l}\text { Mean duration of } \\
\text { response }(\mathrm{min})\end{array}$ & \\
\hline \multicolumn{7}{|l|}{ C-fibers } \\
\hline$(0.47-1.8 \mathrm{~m} / \mathrm{sec})$ & 14 of $16^{a}$ & 17 of 17 & $2.02 \pm 0.48$ & $5-25$ & $30 \pm 3$ & 2 of 7 \\
\hline \multicolumn{7}{|l|}{ A $\delta$-fibers } \\
\hline$(2.2-12.8 \mathrm{~m} / \mathrm{sec})$ & 4 of $6^{b}$ & 6 of 6 & $3.3 \pm 2.3$ & $5-45$ & $18 \pm 4$ & 2 of 7 \\
\hline $\mathrm{A} \beta$-fibers $(23-56 \mathrm{~m} / \mathrm{sec})$ & 0 of 3 & 3 of $9^{c}$ & NA & NA & $28 \pm 3$ & 2 of 13 \\
\hline
\end{tabular}

${ }^{a}$ The two C-fibers that did not respond to ET-1 were low-threshold mechanoreceptors.

${ }^{b}$ Of two A $\delta$-fibers that did not respond to ET-1, one was a low-threshold mechanoreceptor, and the other was a cold A $\delta$-fiber.

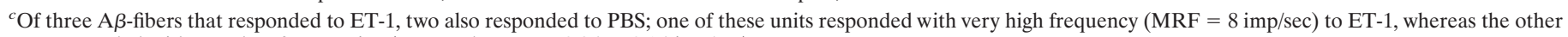
two responded with very low frequencies (averaged $\mathrm{MRF}=0.25 \pm 0.15 \mathrm{imp} / \mathrm{sec}$ ).

$\begin{aligned} & \text { Table 2. Concentration dependence of the average maximum frequency } \\
& \text { of ET-1-induced spike responses during bursts in C-fibers (MxF), and } \\
& \text { the latency to reach MxF }\end{aligned}$
\begin{tabular}{lll}
$\begin{array}{l}\text { Dose of ET-1 } \\
(\mathrm{nmol})\end{array}$ & $\begin{array}{l}\text { Average MxF } \\
\text { (imp/sec, } 1 \text { sec bins) }\end{array}$ & $\begin{array}{l}\text { Time to reach } \\
\text { average MxF (min) }\end{array}$ \\
\hline $16-20(n=7)$ & $14.0 \pm 3.2$ & $7.2 \pm 0.6^{*}$ \\
$8(n=2)$ & $8.0 \pm 2.0$ & $3.1 \pm 2.8$ \\
$2(n=8)$ & $10.0 \pm 3.0$ & $0.26 \pm 0.06$ \\
\hline
\end{tabular}

*Significantly different from $2 \mathrm{nmol}(F=29.7 ; p=0.0004)$.

with progressively stronger stimuli; noxious pinch gave a maximum transient response for both populations of $\mathrm{C}$-fibers of 3-36 imp/sec (mean $14.1 \pm 3.7 \mathrm{imp} / \mathrm{sec})$ (Fig. 3A). These 31 of 33 units can be classified as HTMrs (Handwerker et al., 1991). Two remaining $\mathrm{C}$-units responded equally to both weak and strong mechanical stimulation and can be classified as lowthreshold mechanoresponsive units. Thermal responsiveness was also tested for 11 fibers of the HTMr population (31 of 33), and all responded to thermal stimulation with heat thresholds of between $48^{\circ}$ and $50^{\circ} \mathrm{C}$. These 11 units were also considered as C-PMNs.

All 17 C-units studied after injection of 16-20 nmol of ET-1 into their RFs were activated with latencies to spike response varying from 1.22 to $5.6 \mathrm{~min}$ (mean $3.16 \pm 0.31 \mathrm{~min}$ ) and the duration of responses ranging from 15 to 40 min (mean $30 \pm 3$ min) (Table 1). The temporal pattern of firing induced by ET-1 in these units was usually an early oscillatory bursting pattern, with bursts $10-15 \mathrm{sec}$ in duration, peaking at $\sim 3 \mathrm{~Hz}$, and occurring at $\sim 50 \mathrm{sec}$ intervals. After 5-10 min, the regularity of these burst oscillations was replaced by a more uniform firing of $1-2 \mathrm{~Hz}$ average frequency (Fig. $3 C$ ). The average MRF for all C-fibers tested at these concentrations was $2.02 \pm 0.48 \mathrm{imp} / \mathrm{sec}$. The average MxF (calculated on the basis of maximum frequency peaks during bursts for individual C-fibers) was $14.0 \pm 3.2 \mathrm{imp} /$ sec (Table 2).

Similarly, injection of $1-8 \mathrm{nmol}$ of ET-1 $(n=16)$ provoked spike responses in 14 of 16 units (all HTMr). The two remaining units, both LTMr, did not respond to ET-1 at doses of 1 and 8 nmol, respectively. Although lower average MRF and duration of spike responses were apparent with these lower doses, these differences were only significant when doses of 2 nmol were compared with 16-20 nmol of ET-1 (Fig. 4). Interestingly, the

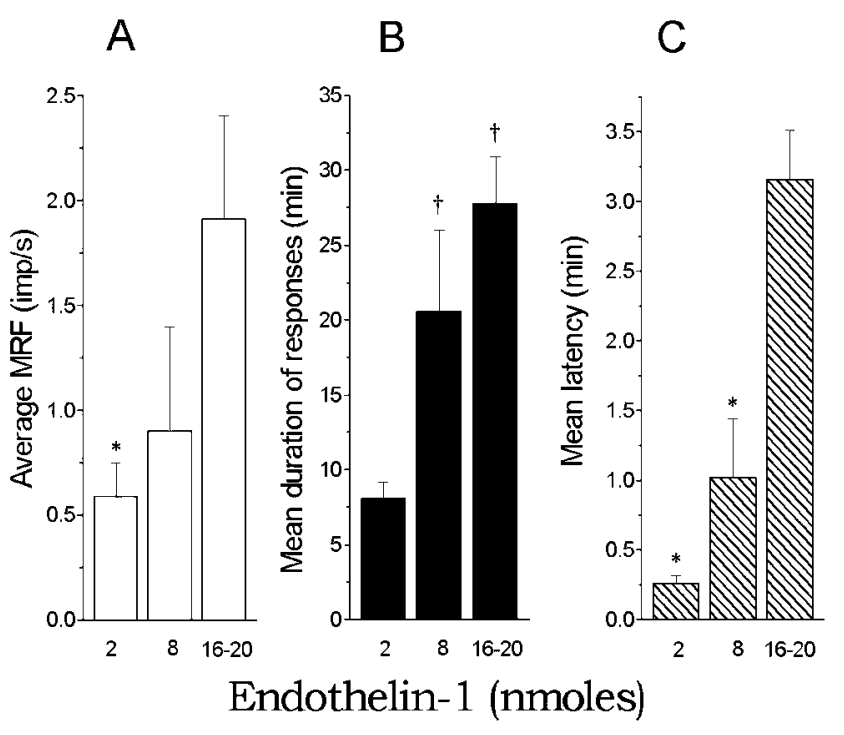

Figure 4. Dose dependence of excitation of C-fibers induced by subcutaneous ET-1 $2 \mathrm{nmol}(n=10), 8 \mathrm{nmol}(n=5)$, and $16-20 \mathrm{nmol}(n=17)$. Shown are the averaged MRF $(A)$, mean duration of responses $(B)$, and mean latency of responses $(C)$. ${ }^{*} p<0.05$ when compared with $16-20$ nmol and ${ }^{\dagger} p<0.05$ when compared with 2 nmol.

latency of responses diminished with dose and at 2 nmol was theshortest among all doses tested, with a mean latency $(0.27 \pm$ $0.06 \mathrm{~min}$ ) that was significantly less than that found at $20 \mathrm{nmol}$ of ET-1 (Fig. 4). Of two C-units injected with $1 \mathrm{nmol}$ of ET-1, one (an HTMr) responded with an MRF of $2.25 \mathrm{imp} / \mathrm{sec}$ and duration of $18 \mathrm{~min}$. The pattern of spike response for doses from 1 to 8 nmol was similar to that observed for $16-20 \mathrm{nmol}$ and was characterized by an initial bursting in regularly spaced episodes that was gradually transformed into sustained firing of decreasing frequency (Fig. 3C).

When ET-1 was coinjected with BQ-123, three units (two C-PMNs) of five tested did not respond. In the other two units, very weak spike activity $(\mathrm{MRF}=0.05-0.09 \mathrm{imp} / \mathrm{sec})$ occurred, of long latency (3-5 $\mathrm{min}$ ) and short duration (5-12 min). Interestingly, in three of five fibers, spike activity developed 48-64 min after coinjection, possibly caused by a waning of the effects of BQ-123, but well beyond the duration of responses to $8 \mathrm{nmol}$ of ET-1 alone ( $20 \mathrm{~min})$ (Fig. 5, Table 1). 


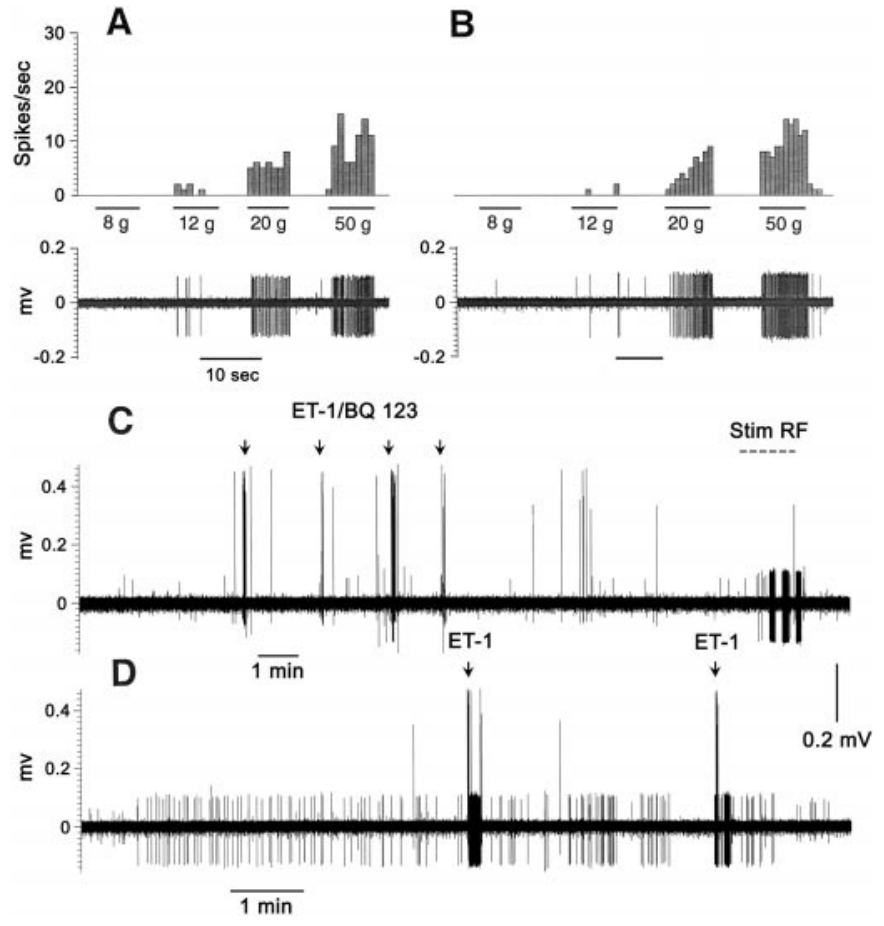

Figure 5. Blockade of HTMr C-fiber (CV $1.18 \mathrm{~m} / \mathrm{sec})$ activation by coinjection of BQ $123(3.2 \mathrm{~mm})$ together with $8 \mathrm{nmol}$ of ET-1. The physiological responses of this unit to graded mechanical stimulation (von Frey hairs) before $(A)$ and after $(B)$ ET-1/BQ-123 are shown. $C$, Four successive injections of ET-1/BQ 123 (10 $\mu$ l each) failed to induce spike responses for a total period of $60 \mathrm{~min}$ ), although the unit maintained its responsiveness to graded mechanical stimulation (Stim $R F$ ). D, Spike activity appeared at $\sim 50$ min after the coinjection of ET-1/BQ-123 and was augmented by successive injections of ET-1 $(2 \mathrm{nmol})$ alone.

\section{Effects of ET-1 on A $\delta$-fibers}

Only two of seven A $\delta$-fibers with RFs that were injected with PBS responded to this vehicle (Table 1). The first, an LTMr, responded to a $50 \mu$ linjection with $3 \mathrm{sec}$ latency, $\mathrm{MRF}=0.22$ imp/sec, and duration $<2$ min. Another A $\delta$-fiber (HTMr) responded to a $40 \mu \mathrm{l}$ injection of PBS with a much shorter period (9.1 $\mathrm{min})$ of much lower MRF (0.6 imp/sec) than the responses to subsequent ET-1 injection (16 nmol) into the RF of this same unit (23 $\mathrm{min}$ and $1.0 \mathrm{imp} / \mathrm{sec}$, respectively). The remaining five $\mathrm{A} \delta$ units did not respond to $10 \mu$ linjections of PBS.

Of the 12 A $\delta$-fibers investigated for the effects of ET-1, 11 had their RFs on the plantar hindpaw, whereas 1 had its RF on the leg. Five of 12 units responded only to intense mechanical stimulation (13-50 gm) and were classified as HTMr, whereas 5 of 12 began to fire with weak mechanical stimuli $(0.72-5.25 \mathrm{gm})$ but increased their responses with increasing stimulus intensity. Of the remaining two A $\delta$-fibers studied, one responded only to weak mechanical stimulation (LTMr), and another responded only to cold stimuli (cold unit). Thermal thresholds for 4 of these 12 fibers were examined and in 3 of 4 fibers were found to range from 42 to $44^{\circ} \mathrm{C}$ (non-noxious); one additional fiber had a thermal threshold of $48^{\circ} \mathrm{C}$ (mechanoheat nociceptor).

Ten of 12 A $\delta$-fibers with RFs that were injected with ET-1 began to fire impulses. Doses of 16-20 nmol of ET-1 produced spike responses in all six A $\delta$-units exposed to these doses (Fig. 6 , Table 1), similar to those observed for $\mathrm{C}$-fibers. The latency to onset of activity ranged from 0.96 to 7.2 min (mean $3.5 \pm 0.12$ min) with response duration varying from 13 to 20 min (mean $=$ $18 \pm 4$ ). The MRF for most ( 5 of 6 ) units ranged from 0.96 to 1.44 $\mathrm{imp} / \mathrm{sec}$ and, in a single instance, reached a maximum of $12.4 \mathrm{imp} / \mathrm{sec}$. The averaged MRF for all six A $\delta$-units was $3.3 \pm 2.3$ $\mathrm{imp} / \mathrm{sec}$, whereas the MxF during bursts (see below) ranged from 7 to $45 \mathrm{imp} / \mathrm{sec}$. These $\mathrm{A} \delta$-units had an irregular response pattern (Fig. 6A) that in most cases resembled the burst-like pattern observed in C-fibers (see above), but were usually of longer duration and had a characteristic shape consisting of a slow crescendo to very high frequency $(29-45 \mathrm{imp} / \mathrm{sec})$ followed by relatively steep frequency decay (Fig. 6B). The total duration of individual bursts ranged from 0.5 to $0.8 \mathrm{~min}$, and their periodicity was $0.92 \pm 0.12 / \mathrm{min}$.

Doses of 1-8 nmol of ET-1 produced spike responses in four of six A $\delta$-fibers tested (all HTMr) with latencies to onset of spiking, duration of response, and MRF comparable to that observed for $\mathrm{C}$-fibers. Of the two A $\delta$-units that did not respond to this dose of ET-1, one was an LTMr and the other was a cold A $\delta$-fiber.

None of four A $\delta$-fibers tested (three HTMr and one cold unit) responded to ET-1/BQ 123 coinjections or to additional ET-1 (2 nmol) administration during the $70 \mathrm{~min}$ period after the initial injection.

\section{Effects of ET-1 on A $\beta$ fibers}

Injections of $40 \mu \mathrm{l}$ PBS (in $10 \mu \mathrm{l}$ aliquots) provoked firing in 2 of 13 units, both of which also responded to injections of ET-1 (Table 1 and see below). One of these units responded with very short latency to the first of four PBS $(10 \mu \mathrm{l})$ injections $(0.43 \mathrm{sec})$ and with $\mathrm{MxF}$ of $65 \mathrm{imp} / \mathrm{sec}$ and $\mathrm{MRF}=40 \mathrm{imp} / \mathrm{sec}$, possibly consistent with an injury-induced discharge. None of four $\mathrm{A} \beta$ units injected with $10 \mu \mathrm{l}$ PBS revealed spiking activity.

The 12 A $\beta$-fibers tested for effects of ET- 1 were of three main functional types: (1) hair follicle (HF) units $(n=3)$ responding to hair bending at the border between glabrous and hairy skin (Fig. 7 , inset), (2) rapidly adapting (RA) units $(n=6)$ responding to touch or light pressure (5-7 gm), and (3) slowly adapting (SA) fibers $(n=3)$ responding with sustained impulse activity to more intense mechanical stimulation (10-20 gm von Frey hair).

In sharp contrast to small-diameter fibers, most $A \beta$-fibers (9 of 12) did not respond to any dose of ET-1 (Fig. $7 C$, Table 1), and in particular, none of the three HF units that responded with highfrequency discharge to mechanical stimulation responded to ET-1. Two of three A $\beta$-units that did respond to 16 nmol of ET- 1 were of the SA type. Both of these units had long ( $\sim 12 \mathrm{~min})$ latencies to onset of spiking, with one unit demonstrating a very low frequency response $(\mathrm{MRF}=0.1 \mathrm{imp} / \mathrm{sec})$, whereas the other fired more intensely $(\mathrm{MxF}=25 \mathrm{imp} / \mathrm{sec}, \mathrm{MRF}=8 \mathrm{imp} / \mathrm{sec})$. The third unit that showed a response to ET-1 was a RA receptor that responded with short latency (1 $\mathrm{min})$ and low MRF (0.4 imp/sec) to both ET-1 (16 nmol) and PBS (40 $\mu \mathrm{l})$ applied to the fleshy pad of the plantar hindpaw.

\section{DISCUSSION}

The results of these experiments demonstrate that subcutaneous injection of ET-1 into the rat plantar hindpaw induces flinching behavior that is accompanied by spike activity in single, nociceptive primary afferents. These effects may be mediated by endothelin receptors on pain fibers because coadministration of an endothelin-A receptor antagonist together with ET-1 blocks both the flinching behavior and spike responses in nociceptors.

Blanching of the skin that immediately follows injection of 
Figure 6. Spike responses in two different HTMr A $\delta$-fibers after subcutaneous injection of $16 \mathrm{nmol}$ of ET-1. $A$, In the first unit (CV $3.08 \mathrm{~m} / \mathrm{sec})$, a bin histogram illustrates the increasing frequency of spiking within the first $5 \mathrm{~min}$ after completion of injections, followed by a gradual decline in spike frequency. Noxious mechanical stimulation performed 9 min after ET-1 injection demonstrates continued responsiveness of the RF of this unit. Inset shows the location of the receptive field of this unit. $B$, In the second unit (CV $5.7 \mathrm{~m} / \mathrm{sec})$, the characteristic bursting pattern of the spike response is shown in a single episode extracted from the full response after injection with 16 nmol of ET-1.
A

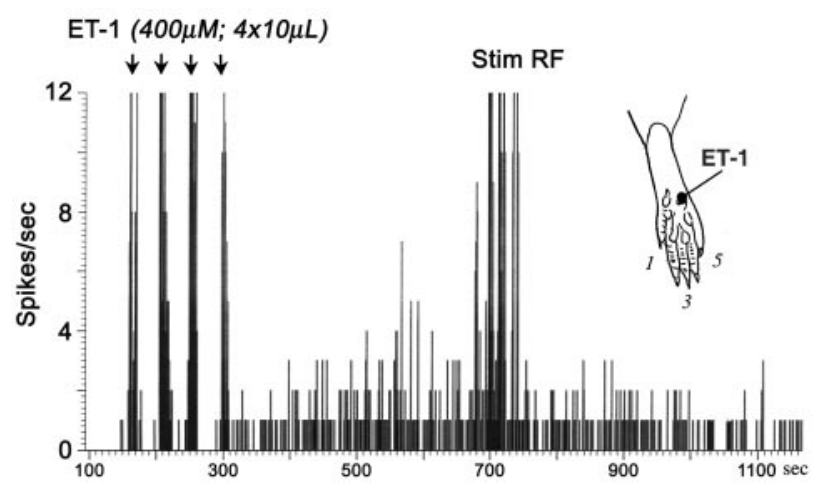

B

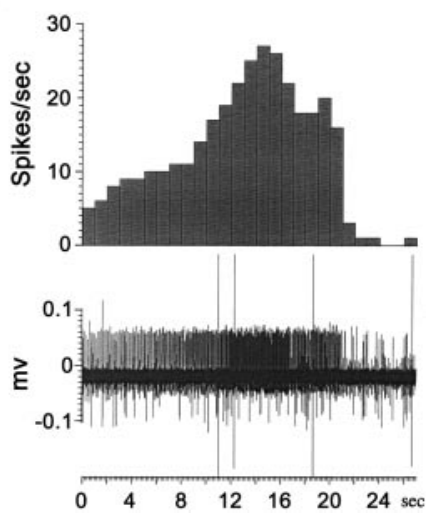

ET-1 into the plantar hindpaw is almost certainly a direct vasoconstrictive effect of ET-1. This vasoconstriction is likely mediated by $\mathrm{ET}_{\mathrm{A}}$ receptors on cutaneous blood vessels, but a possible role for endothelin-B $\left(\mathrm{ET}_{\mathrm{B}}\right)$ receptors cannot be ruled out (Lawrence et al., 1995). In contrast, the more slowly developing erythema and rubor probably reflect a combination of local effects (e.g., limb cooling) and ET-1-mediated release of vasoactive substances either from primary afferent terminals or from other cutaneous cells (e.g., mast cells) as a consequence of primary afferent activation (Crossman et al., 1991). Such proinflammatory, vasoactive substances might contribute directly to, or sustain, the pain behavior and activation of nociceptors (see below).

Although we have previously reported behavioral effects of ET-1 applied to the rat sciatic nerve (Davar et al., 1998; Fareed et al., 2000), this is the first description of an excitatory effect of ET-1 on primary afferent terminals. Although actions on axons cannot be ruled out, we presume that afferent terminals were activated because ET-1 was injected directly into the receptive fields of identified afferents. These effects are likely mediated by

A

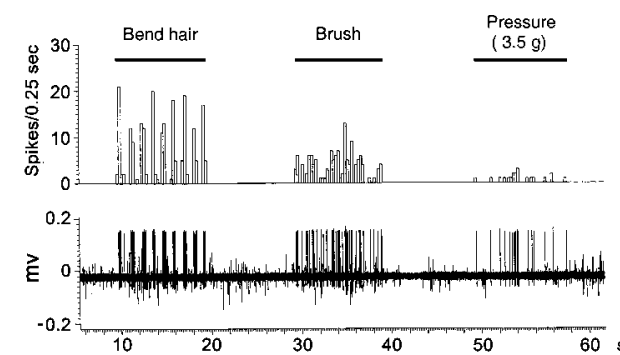

B
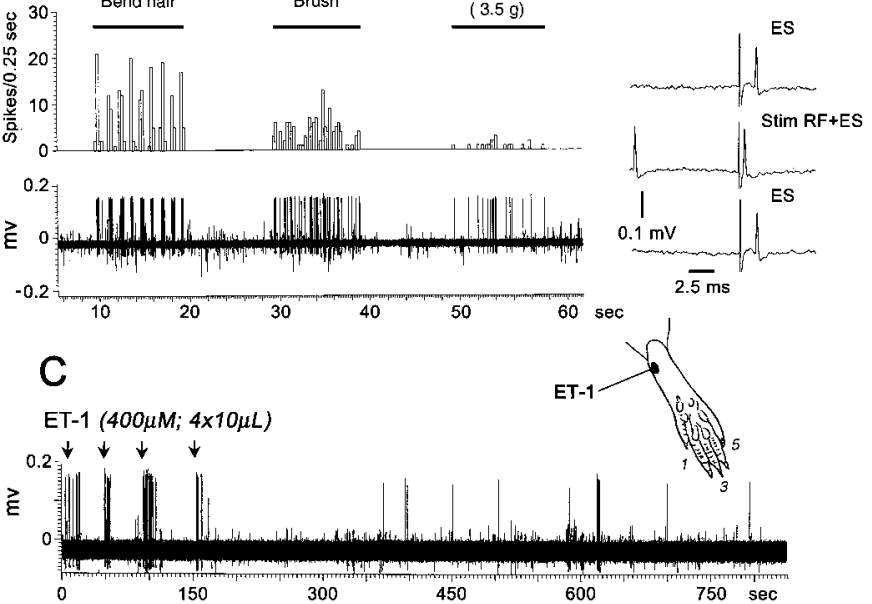

Figure 7. Lack of response of an A $\beta$-fiber (hair follicle afferent, CV 36.4 $\mathrm{m} / \mathrm{sec}$ ) to subcutaneous injection of $16 \mathrm{nmol}$ of ET-1. A, Record of the response of this fiber to hair bending, brush, and von Frey hair (3.5 gm) stimulation of its RF located at the border between hairy and glabrous plantar skin (see inset). $B$, Identification of the unit with the collision method (see Fig. $3 B$ ). $C$, Failure of this same unit to respond to $16 \mathrm{nmol}$ of ET-1 (total dose) into its RF. endothelin receptors located immunocytochemically on primary afferents (Pomonis et al., 2001) or, alternatively, by endothelin receptors located on other supportive cells or vascular cells. More significantly, the majority of $\mathrm{C}$ - and $\mathrm{A} \delta$-fibers, which were predominantly nociceptive, were excited by ET-1, whereas most $\mathrm{A} \beta$-fibers did not respond to ET- 1 . The most important implication of these findings is the confirmation of the nocifensive nature of hindpaw flinching induced by subcutaneous administration of ET-1. Furthermore, and consistent with our previous hypotheses, these results suggest a neural basis for this pain behavior through actions on nociceptive afferents. Although ischemic effects of ET-1 might also contribute to nociceptor activation, acute ischemia usually produces paresthesia rather than pain, presumably as a result of ectopic firing in cutaneous afferents (Mogyoros et al., 1997). In addition, ischemia of visceral C-afferents produces activation with much longer latencies and later peak responses than we have observed here with cutaneous C-fibers injected with ET-1 (Fu et al., 1996; Pan et al., 1997).

Although the time to onset and peak of the spike responses in $\mathrm{C}$ - and $\mathrm{A} \delta$-fibers occurred earlier than the onset and peak of ET-1-induced hindpaw flinching, this is most likely because a critical number of afferents need to be activated to induce flinching behavior. These afferents are probably successively activated by the gradual spread of ET-1, a moderately hydrophobic peptide (Rubanyi and Polokoff, 1994), from subcutaneous sites to the dermis. Another, and coexisting, possibility that was not examined in these experiments, is that the initial spike discharge induces central sensitization to subsequent sensory inputs, thereby prolonging the time course of behavior when compared with the spike responses. Although the latency to spike responses at higher doses might be considered long, for a direct action on nociceptors, several factors argue against this. First, the diff usion of ET- 1 from the subcutaneous space to terminals in the dermis may be rate limiting, and second, we have recently observed that $\mathrm{ET}_{\mathrm{B}}$ receptor blockade in the presence of ET-1 evokes significant increases in flinching and immediate spike responses $(<30 \mathrm{sec})$, consistent with inhibitory effects of the $\mathrm{ET}_{\mathrm{B}}$ receptor on pain behavior and nociceptor activation (Khodorova et al., 2001; our unpublished results). The reduction in latency to onset of spike responses with reduced dose may have been a consequence of ET-1-mediated venous pooling and edema that occurs as dose is increased, reducing access of ET-1 to terminals (Piovezan et al., 2000). Although the mean and maximum frequency of ET-1induced spike responses in $\mathrm{C}$ - and $\mathrm{A} \delta$-fibers is lower than that observed with noxious pinch, spatial integration of fibers acti- 
vated by ET-1 spreading subcutaneously after injection, and a pattern of firing (bursting) that is known to sensitize second order spinal neurons (Schouenborg and Dickenson, 1985), may have contributed to the observed nocifensive response. Despite the relatively high concentrations of ET- 1 used in these studies, the local concentrations at receptor-containing tissues are unknown, and importantly, the ET-1 concentration reached in diseased tissue (e.g., in vertebral tissues at the site of prostate or breast cancer metastasis) that is required to induce pain is also unknown. The effective concentration might indeed be low $(<100$ $\mu \mathrm{M}$ ), yet within the range that can induce spiking in C-fibers. In humans with cancer metastases, small amounts of ET- 1 might also sensitize fibers to subsequent noxious or non-noxious stimuli, as has been described in animals (Piovezan et al., 1998, 2000; Ferreira et al., 1989).

Nociceptive $\mathrm{C}$ - and A $\delta$-fibers had very similar spike response characteristics when exposed to ET-1 injection. Although thermal thresholds appeared to be somewhat reduced in $\mathrm{A} \delta$ - when compared with $\mathrm{C}$-fibers, the small number of $\mathrm{A} \delta$-units in which thermal thresholds were determined was insufficient to establish any significance to this difference.

In contrast with the effects of ET- 1 on nociceptors, $\mathrm{A} \beta$-fibers failed to respond to ET-1 injected into their receptive fields. Although spike responses were observed in a few units, they developed with much longer latencies and had markedly lower mean and maximum frequencies than were observed for $\mathrm{C}$ - and A $\delta$-fibers. Two of the three A $\beta$-units that did respond to ET- 1 also responded to PBS injection, suggesting an injury-related or mechanical, (e.g., volume of injection, needle damage) effect of the procedure per se in those instances. This lack of response to ET- 1 in $\mathrm{A} \beta$-fibers is consistent with an absence or low abundance of "excitatory" $\mathrm{ET}_{\mathrm{A}}$ receptors on $\mathrm{A} \beta$-fibers. Of course this does not exclude the possibility that other, nonactivating endothelin receptor subtypes (e.g., endothelin-C) might be found on $\mathrm{A} \beta$ fibers. The failure of $A \beta$-fibers to respond to ET- 1 supports the idea that the actions of ET-1 on primary afferents are selective for nociceptors and that the observed behavior (hindpaw flinching) is pain related.

Finally, the blockade of ET-1-induced pain behavior, and spike responses in nociceptors, by an $\mathrm{ET}_{\mathrm{A}}$ receptor antagonist clearly establishes a specific action of ET-1 for these phenomena. Although concentrations well in excess of the $\mathrm{K}_{\mathrm{I}}$ that might lead to actions at the $\mathrm{ET}_{\mathrm{B}}$ receptor were used to study the effects of BQ-123, our recent results suggest that activation of the $\mathrm{ET}_{\mathrm{B}}$ receptor would enhance rather than inhibit flinching and spike responses (Khodorova et al., 2001; our unpublished data). Taken together with recent studies demonstrating the presence of $\mathrm{ET}_{\mathrm{A}}$ receptors on primary afferents (Pomonis et al., 2001), these results and our previous reports of the actions of ET-1 on sciatic nerve suggest that ET-1 is acting through $\mathrm{ET}_{\mathrm{A}}$ receptors found on nociceptive primary afferents to produce pain behavior. The observations that $\mathrm{C}$ - and $\mathrm{A} \delta$-fibers that did not respond to ET- 1 were non-nociceptive lends further support to the modal specificity of receptor action.

\section{REFERENCES}

Carducci MA, Bowling MK, Rogers T, Leahy TL, Janus TJ, Padley RJ, Nelson JB (1998) Endothelin receptor antagonist, ABT-627, for prostate cancer: initial trial results. Presented at American Association for Cancer Research Meeting, Indian Wells, CA, December. Abstr. C-24.
Crossman DC, Brain SD, Fuller RW (1991) Potent vasoactive properties of endothelin 1 in human skin. J Appl Physiol 70:260-266.

Dahlof B, Gustafsson D, Hedner T, Jern S, Hannsson L (1990) Regional hemodynamic effects of endothelin-1 in rat and man: unexpected adverse effects. J Hypertens 8:811-818.

Davar G, Hans G, Fareed MU, Sinnott C, Strichartz G (1998) Behavioral signs of acute pain produced by application of endothelin- 1 to rat sciatic nerve. NeuroReport 9:2279-2283.

De-Melo JD, Tonussi CR, D'Orleans-Juste P, Rae GA (1998) Articular nociception induced by endothelin-1, carrageenan and LPS in naive and previously inflamed knee-joints in the rat: inhibition by endothelin receptor antagonists. Pain 77:261-269.

Fareed MU, Hans G, Atanda A, Strichartz G, Davar G (2000) Pharmacologic characterization of acute pain behavior produced by application of endothelin-1 to rat sciatic nerve. J Pain 1:46-53.

Ferreira SH, Romitelli M, de Nucci G (1989) Endothelin-1 participation in overt and inflammatory pain. J Cardiovasc Pharmacol 13 [Suppl 5]:S220-S222.

Fu LW, Pan HL, Pitsillides KF, Longhurst JC (1996) Hypoxia does not directly stimulate ischemically sensitive abdominal visceral afferents during ischemia. Am J Physiol 271:H261-H266.

Giaid A, Gibson SJ, Ibrahim BN, Legon S, Bloom SR, Yanagisawa M, Masaki T, Varndell IM, Polak JM (1989) Endothelin 1, an endothelium-derived peptide, is expressed in neurons of the human spinal cord and dorsal root ganglia. Proc Natl Acad Sci USA 86:7634-7638.

Graido-Gonzalez E, Doherty JC, Bergreen EW, Organ G, Telfer M, McMillen MA (1998) Plasma endothelin-1, cytokine, and prostaglandin E2 levels in sickle cell disease and acute vaso-occlusive sickle crisis. Blood 92:2551-2555.

Hammerman SI, Kourembanas Conca TJ, Tucci M, Brauer M, Farber HW (1997) Endothelin-1 production during the acute chest syndrome in sickle cell disease. Am J Respir Crit Care Med 156:280-285.

Handwerker HO, Kilo S, Reeh PW (1991) Unresponsive afferent nerve fibres in the sural nerve of the rat. J Physiol (Lond) 435:229-242.

Huang JH, Thalhammer JG, Raymond SA, Strichartz GR (1997) Susceptibility to lidocaine of impulses in different somatosensory afferent fibers of rat sciatic nerve. J Pharmacol Exp Ther 282:802-811.

Iggo A (1958) Electrophysiolgical identification of single nerve fibers, with particular reference to the slowest-conducting vagal afferent fibres in the cat. J Physiol (Lond) 142:110-126.

Ishikawa K, Fukami T, Nagase T, Fujita K, Hayama T, Niiyama K, Mase T, Ihara M, Yano M (1992) Cyclic pentapeptide endothelin antagonists with high ETA selectivity. Potency- and solubility-enhancing modifications. J Med Chem 35:2139-2142.

Jarvis MF, Wessale JL, Z hu CZ, Lynch JJ, Dayton BD, Calzadilla SV, Padley RJ, Opgenorth TJ, Kowaluk EA (2000) ABT-627, an endothelin ET(A) receptor-selective antagonist, attenuates tactile allodynia in a diabetic rat model of neuropathic pain. Eur J Pharmacol 388:29-35.

Kar S, Chabot JG, Quirion R (1991) Quantitative autoradiographic localisation of $\left[{ }^{125} \mathrm{I}\right]$ endothelin-1 binding sites in spinal cord and dorsal root ganglia of the rat. Neursoci Lett 133:117-120.

Khodorova A, Fareed MU, Strichartz GR, Davar G (2001) Endothelin-B receptor mediated modulation of pain-like behavior induced by subcutaneous injection of endothelin-1 into the rat plantar hindpaw. Paper presented at the 20th Annual Scientific Meeting of the Am Pain Society, Phoenix, AZ, April.

Lawrence E, Siney L, Wilsoncroft P, Knock GA, Terenghi G, Polak JM, Brain SD (1995) Evidence for ETA and ETB receptors in rat skin and an investigation of their function in the cutaneous microvasculature. Br J Pharmacol 115:840-844.

Leem JW, Willis WD, Chung JM (1993) Cutaneous sensory receptors in the rat foot. J Neurophysiol 69:1684-1699.

Marsault R, Feolde E, Frelin C (1993) Receptor externalization determines sustained contractile responses to endothelin- 1 in the rat aorta. Am J Physiol 264:C687-693.

Mogyoros I, Kiernan MC, Burke D, Bostock H (1997) Excitability changes in human sensory and motor axons during hyperventilation and ischemia. Brain 120:317-325.

Pan HL, Zeisse ZB, Pitsillides KF, Longhurst JC (1997) Spatiotemporal aspects of sympathetic C-fiber afferent activity in pressor reflex during abdominal ischemia. Am J Physiol 272:H1928-H1936.

Piovezan AP, D’Orleans-Juste P, Tonussi CR, Rae GA (1997) Endothelins potentiate formalin-induced nociception and paw edema in mice. Can J Physiol Pharmacol 75:596-600.

Piovezan AP, D'Orleans-Juste P, Tonussi CR, Rae GA (1998) Effects of endothelin-1 on capsaicin-induced nociception in mice. Eur J Pharmacol 351:15-22. 
Piovezan AP, D'Orleans-Juste P, Souza GE, Rae GA (2000) Endothelin-1-induced ET(A) receptor-mediated nociception, hyperalgesia and oedema in the mouse hind-paw: modulation by simultaneous $\mathrm{ET}(\mathrm{B})$ receptor activation. $\mathrm{Br} \quad \mathrm{J}$ Pharmacol 129:961-968.

Pomonis JD, Rogers SD, Peters CM, Ghilardi JR, Mantyh PW (2001) Expression and localization of endothelin receptors: implications for the involvement of peripheral glia in nociception. J Neurosci 21:999-1006.

Raffa R, Schupsky J, Jacoby H (1996a) Endothelin-induced nociception in mice: mediation by $\mathrm{ET}_{\mathrm{A}}$ and $\mathrm{ET}_{\mathrm{B}}$ Receptors. J Pharmacol Exp Ther 276:647-651.

Raffa R, Schupsky J, Lee D, Jacoby H (1996b) Characterization of endothelin-induced nociception in mice: evidence for a mechanistically distinct analgesic model. J Pharmacol Exp Ther 278:1-7.

Rubanyi GM, Polokoff A (1994) Endothelins: molecular biology, biochemistry, pharmacology, physiology, and pathophysiology. Pharmacol Rev 48:325-415.

Sanders KH, Zimmermann M (1986) Mechanoreceptors in rat glabrous skin: redevelopment of function after nerve crush. J Neurophysiol 55:644-659.

Schouenborg J, Dickenson AH (1985) Effects of a distant noxious stimulation on $\mathrm{A}$ and $\mathrm{C}$ fibre evoked flexion reflexes and neuronal activity in the dorsal horn of the rat. Brain Res 328:23-32.

Zimmermann M (1983) Ethical guidelines for investigations of experimental pain in conscious animals. Pain 16:109-110. 